\title{
Interactions between transposable elements for insertion in the Drosophila melanogaster genome
}

\section{Biémont and \\ C. Gautier}

Laboratoire de Biologie des populations. Université Claude-Bernard, Lyon 1, 69622 Villeurbanne, France.

Using in situ hybridization to polytene salivary gland chromosomes, we have registered the co-occurrences of insertions of the four mobile elements, copia, $m d g-1, I$ and $P$ in the whole genomes of 17 highly-inbred lines of Drosophila melanogaster (the insertions in the centromeric regions were excluded); these elements differ in structure, DNA sequence and profile of developmental transcription. The mdg-1 and $P$ elements tend to avoid each other on the $X$ chromosomes but not on the autosomes; copia and mdg-1, two copia-like elements, show an excess of co-occurrences on the $2 \mathrm{~L}$ and $3 \mathrm{R}$ chromosome arms but not on the $\mathrm{X}$ chromosomes. The pairs $\mathrm{mdg}-1 / I, I /$ copia, $I / P$ and $c o p i a / P$ do not show any kind of interaction. Populational studies are thus necessary to obtain complete accurate information on interactions between transposable elements for their sites of insertion in a genome.

\section{INTRODUCTION}

Many organisms ranging from bacteria, insects, nematodes and plants to man carry in their genome numerous families of transposable elements which represent an important source of genetic variability. The molecular analysis of these mobile elements has yielded a great amount of data on their structure, DNA sequence and genomic location. Although the extent to which various elements interact with each other is a central question in understanding their biology, there is still only scarce information on the behaviour of different elements in a particular genome. Differences in DNA structure and sequence of the copia (Emori et al., 1985), mdg-1 (a copia-like element; Ilyin, Chmeliauskaite and Georgiev, 1980; Tchurikov et al., 1981), I (Fawcett et al., 1986; Di Nocera and Casari, 1987) and $P$ (O'Hare and Rubin, 1983) suggest that these elements may insert in different genomic locations. However, only few and partial data on co-occurrences in location in the Drosophila genome are available at a populational level (Montgomery and Langley, 1983). Such data are indeed difficult to obtain since the in situ hybridization technique commonly used to precisely detect insertion sites is difficult to handle when differentiating various elements in the same genome. This can be done, however, in highlyinbred lines whose highly-homozygous individuals present no or very low insertion polymorphism for mobile elements (Biémont and Aouar, 1987; Biémont and Gautier, 1987; Biémont and Gautier, 1988). Here we have analysed the co-occurrences of insertions of four mobile elements ( $m d g-1$, copia, $I$ and $P$ ) in the genomes of 17 highly-inbred lines of $D$. melanogaster.

\section{MATERIALS AND METHODS}

Seventeen inbred lines of $D$. melanogaster were initiated from flies randomly taken from a Russian Drosophila population (Biémont and Aouar, 1987); they were maintained by one sib pair every generation. At generation 52 each inbred line was analysed for localization of copia, $m d g-1, I$ and $P$ mobile elements in its genome by in situ hybridization of biotinylated DNA probes on giant chromosomes. The DNA was nick-translated with biotinylated 11-dUTP (Rigby et al. 1977; LangerSafer, Levine and Ward, 1982) and used in the in situ hybridization technique as previously described (Biémont, 1986; see fig. 1 for an example of in situ hybridization). For a complete description of the polymorphism of localization of the $m d g-1$, copia, $I$ and $P$ elements see Biémont (1986), Biémont and Aouar (1987), Biémont and Gautier (1988), Biémont, Gautier and Heizmann (1988). In these works it was found that the mean 
copy number per haploid genome of each element on the inbred lines were close and equal to 17.8 for copia, 16.8 for $m d g-1,17.5$ for $I$ and 18.6 for $P$. The $P$ element differed from the other three for variance in copy number and in the distribution of the number of insertion site occurrences. A genomic control of copy number (a compensatory effect among chromosome arms) was detected for copia, $m d g-1$ and $I$, but not for $P$, reflecting the mechanisms of transposition of these elements: a reverse transcriptase for copia, $m d g-1$ and $I$, a transposase for $P$ (Biémont and Gautier, 1988; Biémont, Gautier and Heizmann, 1988). From the precise localisation of insertions of the elements in the inbred lines which were considered as random gametes of the initial population (Biémont and Gautier, 1987), we estimated that the probabilities that a site observed in the population is heterozygous in one individual were equal to 0.90 , $0.86,0.92$ and 0.94 for the copia, $m d g-1, I$ and $P$ elements respectively. Table 1 presents a summary of the occurrences of the insertion sites detected on all the chromosome arms of the 17 inbred lines.

\section{RESULTS}

Co-occurrences may refer to two different phenomena (i) there exists chromosomal environ- ment (DNA sequences, local chromatin structure, etc.) suitable for insertion of different element families so that the probability of observing two elements in the same site is increased, (ii) the presence of one element in a site creates a chromosomal environment particularly suitable (or unsuitable) for insertion of another element (facilitation and exclusion phenomenon). We have developed two statistical tests to discriminate between these two possibilities. The main idea of these tests is based on the fact that the first phenomenon increases the similarity between the insertion patterns of the element families considered, even when dealing with two different haploid genomes. Thus a first model tests all similarities between the insertion patterns of two element families; a second model addresses specifically the similarities occurring in a same genome (insertion of two or more elements in the same hybridization site in a given line). So, common insertion sites can be detected by the first model while the second detects facilitation and exclusion events.

The assumption of the first model (the null hypothesis) is that observed insertion sites of an element in a population are randomly drawn from the possible insertion sites. As a decent estimate of the number of sites that can be detected by the in situ hybridization technique we used 400 according to Belyaeva, Ananiev and Gvozdev (1984); this

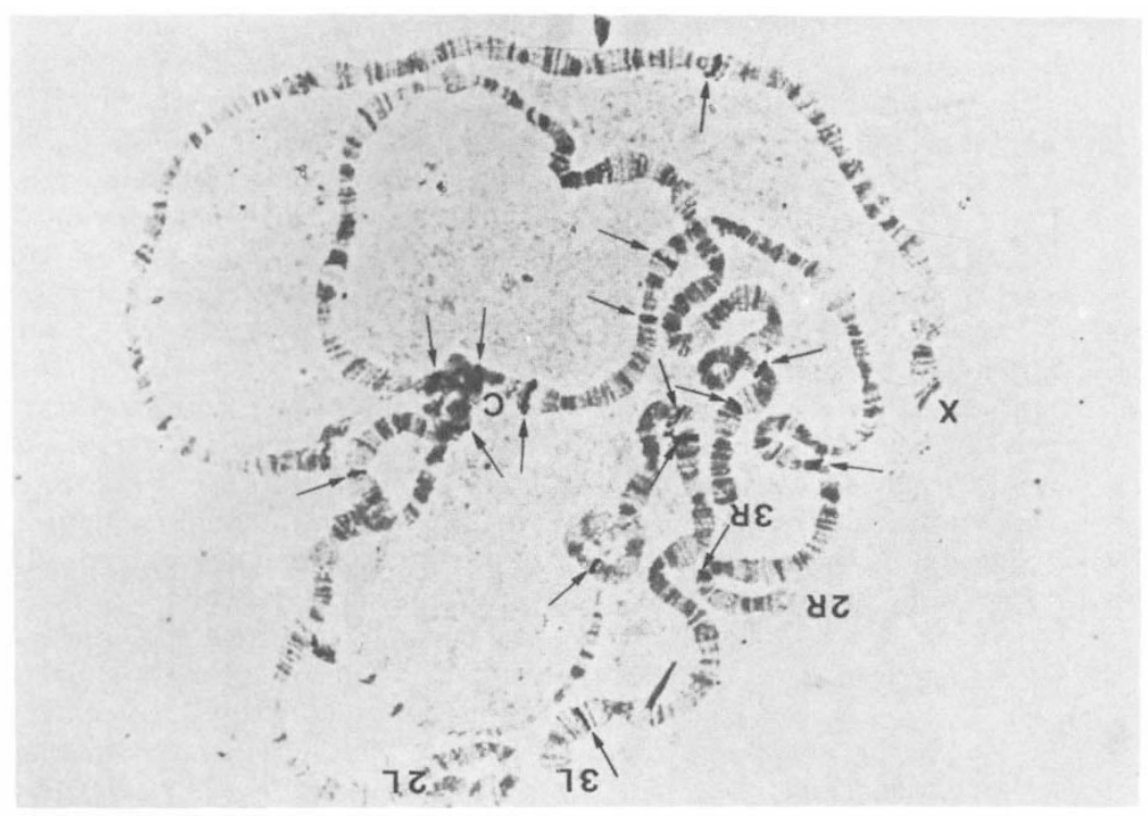

Figure 1 Picture of in situ hybridization of biotinylated $m d g-1$ DNA to salivary gland polytene chromosomes. The arrows indicate $m d g-1$ insertions. C, centromeric region. 

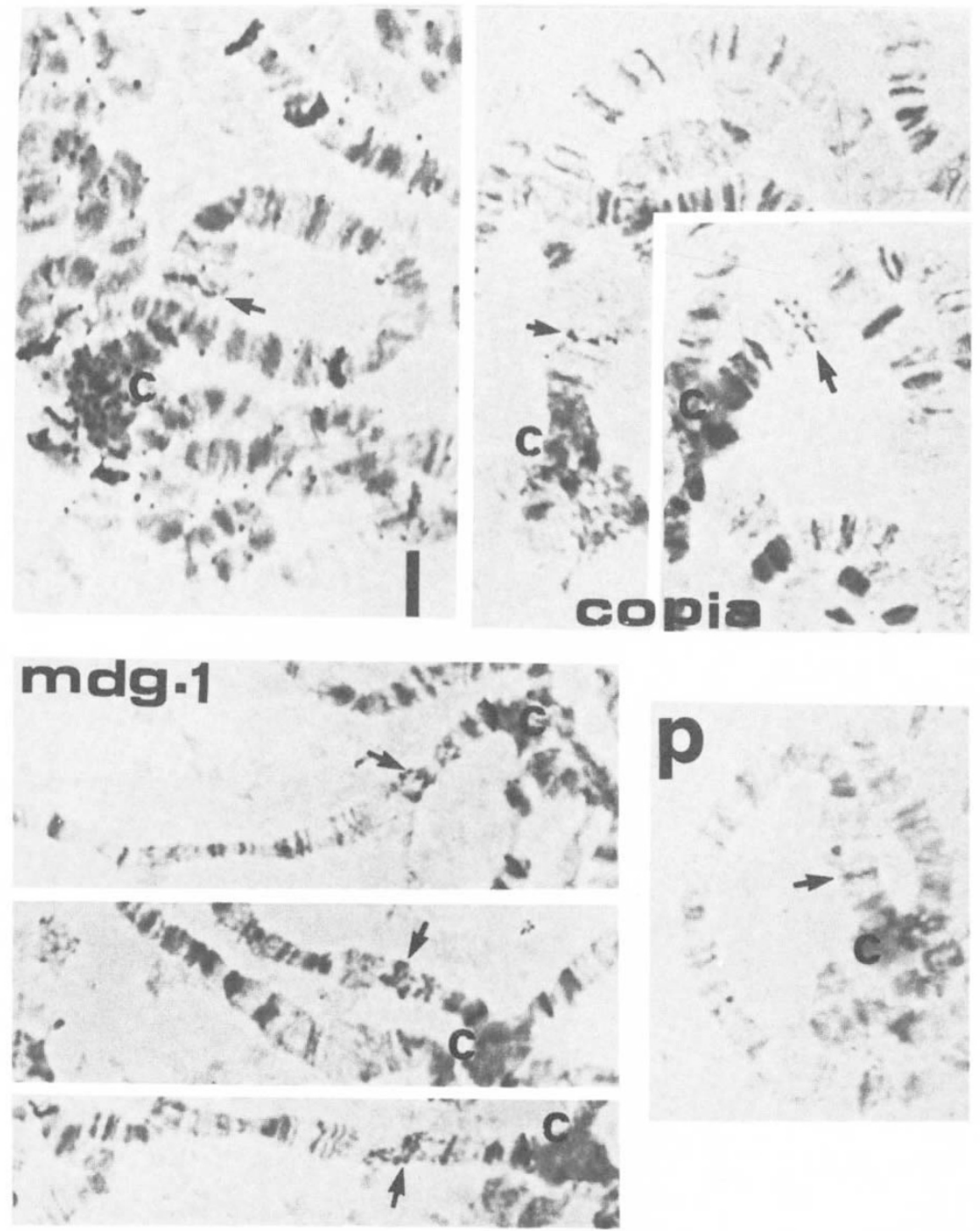

Figure 2 Examples of multiple insertions of four mobile elements (copia, mdg-1, $I, P$ ) in the $42 \mathrm{~B}$ region of the $2 \mathrm{R}$ chromosome arm as revealed by in situ hybridization with biotinylated-DNA probes. The arrows indicate the insertions in the $42 \mathrm{~B}$ region. $C$, centromeric region; notice the high number of hybridization points revealed with the $I$ probe in the centromeric region.

number is considerably less than the number of polytene bands but it is of reasonable value when dealing with radio-active probes. Although biotin leads to more precise localizations (see the picture in Biémont and Terzian, 1986, and fig. 1) and hence allows more possible insertion sites to be detected, we cannot usually distinguish hybridization sites to different positions within a lettered subdivision, even though each division may contain over $200 \mathrm{~kb}$ of DNA; moreover our model 2 takes account of the fact that multiple occupations may arise from the reduced number of sites that can be distinguished by the in situ technique; see fig. 2 for an example of multiple insertions detected in the 42B region of the $2 \mathrm{R}$ chromosomes. Then, let $N_{\mathrm{A}}$ and $N_{\mathrm{B}}$ be the respective observed numbers of insertion sites for two $\mathrm{A}$ and $\mathrm{B}$ elements in the population (constituted by the ensemble of lines), and $N_{\mathrm{AB}}$ the number of observed common sites. Since the null hypothesis implies the independency of the two elements, the first test compares $N_{\mathrm{AB}}$ to the number of common sites expected when these sites 
Table 1 Sites of insertion and their occurrences in the chromosome arms of the 17 inbred lines for the elements copia, mdg-1, $I$ and $P$. Only sites with co-occurrences of at least two elements within line or between lines were recorded.

\begin{tabular}{|c|c|c|c|c|c|c|c|c|c|c|c|}
\hline $\begin{array}{l}\text { Chromosome } \\
\text { arm }\end{array}$ & Sites & $\begin{array}{l}\mathrm{El} \\
I\end{array}$ & nts & copia & $P$ & $I / M$ & $I /$ copia & $I / P$ & $M /$ copia & $M / P$ & copia/P \\
\hline \multirow[t]{20}{*}{$X$} & $01 A$ & 3 & 0 & 2 & 3 & 0 & 2 & 0 & 0 & 0 & 0 \\
\hline & $03 A$ & 0 & 6 & 0 & 6 & 0 & 0 & 0 & 0 & 1 & 0 \\
\hline & $03 F$ & 1 & 1 & 2 & 1 & 0 & 0 & 0 & 0 & 0 & 0 \\
\hline & $04 A$ & 2 & 2 & 0 & 0 & 1 & 0 & 0 & 0 & 0 & 0 \\
\hline & $04 D$ & 0 & 3 & 0 & 2 & 0 & 0 & 0 & 0 & 0 & 0 \\
\hline & $04 E$ & 0 & 2 & 0 & 1 & 0 & 0 & 0 & 0 & 0 & 0 \\
\hline & $06 A$ & 0 & 1 & 0 & 2 & 0 & 0 & 0 & 0 & 0 & 0 \\
\hline & $07 A$ & 0 & 0 & 1 & 1 & 0 & 0 & 0 & 0 & 0 & 0 \\
\hline & $07 B$ & 1 & 4 & 0 & 0 & 0 & 0 & 0 & 0 & 0 & 0 \\
\hline & $07 C$ & 1 & 0 & 0 & 1 & 0 & 0 & 0 & 0 & 0 & 0 \\
\hline & $07 D$ & 4 & 0 & 0 & 1 & 0 & 0 & 0 & 0 & 0 & 0 \\
\hline & $07 F$ & 0 & 1 & 0 & 1 & 0 & 0 & 0 & 0 & 0 & 0 \\
\hline & $08 E$ & 1 & 0 & 0 & 1 & 0 & 0 & 0 & 0 & 0 & 0 \\
\hline & $11 C$ & 0 & 1 & 0 & 1 & 0 & 0 & 0 & 0 & 0 & 0 \\
\hline & $12 E$ & 2 & 0 & 4 & 2 & 0 & 1 & 0 & 0 & 0 & 1 \\
\hline & $12 F$ & 0 & 0 & 4 & 1 & 0 & 0 & 0 & 0 & 0 & 0 \\
\hline & $16 F$ & 3 & 3 & 0 & 0 & 0 & 0 & 0 & 0 & 0 & 0 \\
\hline & $19 A$ & 0 & 0 & 2 & 2 & 0 & 0 & 0 & 0 & 0 & 0 \\
\hline & $19 B$ & 2 & 0 & 1 & 2 & 0 & 0 & 0 & 0 & 0 & 0 \\
\hline & $19 F$ & 4 & 12 & 0 & 1 & 3 & 0 & 0 & 0 & 0 & 0 \\
\hline \multirow[t]{15}{*}{$2 L$} & $22 A$ & 0 & 8 & 7 & 0 & 0 & 0 & 0 & 6 & 0 & 0 \\
\hline & $22 C$ & 0 & 0 & 1 & 2 & 0 & 0 & 0 & 0 & 0 & 0 \\
\hline & $24 D$ & 0 & 0 & 10 & 2 & 0 & 0 & 0 & 0 & 0 & 1 \\
\hline & $25 A$ & 0 & 4 & 3 & 2 & 0 & 0 & 0 & 3 & 1 & 1 \\
\hline & $29 A$ & 0 & 0 & 2 & 1 & 0 & 0 & 0 & 0 & 0 & 0 \\
\hline & $33 A$ & 1 & 3 & 1 & 1 & 0 & 0 & 0 & 1 & 1 & 0 \\
\hline & $33 C D$ & 1 & 0 & 3 & 0 & 0 & 1 & 0 & 0 & 0 & 0 \\
\hline & $33 F$ & 0 & 0 & 1 & 1 & 0 & 0 & 0 & 0 & 0 & 0 \\
\hline & $34 D$ & 0 & 0 & 3 & 5 & 0 & 0 & 0 & 0 & 0 & 1 \\
\hline & $35 A B$ & 0 & 1 & 3 & 0 & 0 & 0 & 0 & 0 & 0 & 0 \\
\hline & $35 E$ & 0 & 0 & 1 & 2 & 0 & 0 & 0 & 0 & 0 & 1 \\
\hline & $36 B$ & 2 & 6 & 1 & 2 & 0 & 0 & 1 & 1 & 0 & 0 \\
\hline & $36 E F$ & 2 & 0 & 0 & 1 & 0 & 0 & 0 & 0 & 0 & 0 \\
\hline & $37 C$ & 0 & 0 & 1 & 4 & 0 & 0 & 0 & 0 & 0 & 0 \\
\hline & $37 E$ & 0 & 0 & 1 & 1 & 0 & 0 & 0 & 0 & 0 & 0 \\
\hline \multirow[t]{26}{*}{$2 R$} & $39 A$ & 0 & 0 & 1 & 1 & 0 & 0 & 0 & 0 & 0 & 0 \\
\hline & $42 A$ & 1 & 5 & 4 & 2 & 0 & 0 & 0 & 0 & 1 & 0 \\
\hline & $42 B$ & 2 & 3 & 10 & 1 & 0 & 1 & 0 & 2 & 0 & 1 \\
\hline & $43 A$ & 0 & 1 & 1 & 0 & 0 & 0 & 0 & 0 & 0 & 0 \\
\hline & $44 D$ & 0 & 3 & 1 & 0 & 0 & 0 & 0 & 0 & 0 & 0 \\
\hline & $46 A$ & 2 & 1 & 0 & 1 & 0 & 0 & 1 & 0 & 0 & 0 \\
\hline & $46 B$ & 6 & 3 & 0 & 3 & 1 & 0 & 1 & 0 & 1 & 0 \\
\hline & $47 A$ & 3 & 0 & 0 & 1 & 0 & 0 & 0 & 0 & 0 & 0 \\
\hline & $47 B C$ & 3 & 3 & 0 & 0 & 0 & 0 & 0 & 0 & 0 & 0 \\
\hline & $47 D$ & 0 & 0 & 3 & 1 & 0 & 0 & 0 & 0 & 0 & 0 \\
\hline & $50 C$ & 1 & 0 & 0 & 1 & 0 & 0 & 0 & 0 & 0 & 0 \\
\hline & $51 \mathrm{~A}$ & 1 & 1 & 0 & 1 & 0 & 0 & 0 & 0 & 0 & 0 \\
\hline & $52 A$ & 0 & 7 & 1 & 0 & 0 & 0 & 0 & 0 & 0 & 0 \\
\hline & $53 A B$ & 3 & 5 & 0 & 0 & 1 & 0 & 0 & 0 & 0 & 0 \\
\hline & $53 B$ & 0 & 0 & 1 & 2 & 0 & 0 & 0 & 0 & 0 & 0 \\
\hline & $53 C$ & 0 & 0 & 1 & 4 & 0 & 0 & 0 & 0 & 0 & 0 \\
\hline & $53 C D$ & 1 & 3 & 0 & 0 & 0 & 0 & 0 & 0 & 0 & 0 \\
\hline & $56 E$ & 1 & 0 & 0 & 1 & 0 & 0 & 0 & 0 & 0 & 0 \\
\hline & $56 F$ & 5 & 3 & 0 & 0 & 0 & 0 & 0 & 0 & 0 & 0 \\
\hline & $57 A$ & 4 & 0 & 6 & 1 & 0 & 2 & 0 & 0 & 0 & 0 \\
\hline & $57 B$ & 1 & 0 & 4 & 0 & 0 & 0 & 0 & 0 & 0 & 0 \\
\hline & $57 E$ & 0 & 1 & 0 & 1 & 0 & 0 & 0 & 0 & 0 & 0 \\
\hline & $57 F$ & 0 & 1 & 2 & 0 & 0 & 0 & 0 & 0 & 0 & 0 \\
\hline & $59 A$ & 1 & 0 & 0 & 1 & 0 & 0 & 0 & 0 & 0 & 0 \\
\hline & $59 D$ & 0 & 1 & 0 & 1 & 0 & 0 & 0 & 0 & 0 & 0 \\
\hline & $59 E$ & 2 & 0 & 0 & 2 & 0 & 0 & 1 & 0 & 0 & 0 \\
\hline \multirow[t]{2}{*}{$3 L$} & $61 C$ & 0 & 0 & 2 & 1 & 0 & 0 & 0 & 0 & 0 & 0 \\
\hline & $61 D$ & 2 & 0 & 2 & 3 & 0 & 0 & 1 & 0 & 0 & 0 \\
\hline
\end{tabular}


Table 1 continued

\begin{tabular}{|c|c|c|c|c|c|c|c|c|c|c|c|}
\hline & $61 E$ & 1 & 0 & 0 & 1 & 0 & 0 & 0 & 0 & 0 & 0 \\
\hline & $61 F$ & 2 & 4 & 0 & 0 & 0 & 0 & 0 & 0 & 0 & 0 \\
\hline & $62 F$ & 3 & 0 & 1 & 0 & 0 & 0 & 0 & 0 & 0 & 0 \\
\hline & $63 A$ & 0 & 0 & 1 & 1 & 0 & 0 & 0 & 0 & 0 & 1 \\
\hline & $64 C$ & 0 & 1 & 2 & 1 & 0 & 0 & 0 & 0 & 0 & 1 \\
\hline & $65 A$ & 0 & 1 & 0 & 2 & 0 & 0 & 0 & 0 & 0 & 0 \\
\hline & $65 F$ & 0 & 1 & 0 & 1 & 0 & 0 & 0 & 0 & 0 & 0 \\
\hline & $66 A$ & 1 & 0 & 1 & 0 & 0 & 0 & 0 & 0 & 0 & 0 \\
\hline & $66 C$ & 8 & 0 & 1 & 1 & 0 & 0 & 0 & 0 & 0 & 1 \\
\hline & $67 A$ & 1 & 0 & 2 & 1 & 0 & 0 & 0 & 0 & 0 & 0 \\
\hline & $67 E$ & 0 & 1 & 2 & 0 & 0 & 0 & 0 & 0 & 0 & 0 \\
\hline & $68 A$ & 0 & 0 & 1 & 1 & 0 & 0 & 0 & 0 & 0 & 0 \\
\hline & $68 D$ & 0 & 6 & 0 & 1 & 0 & 0 & 0 & 0 & 0 & 0 \\
\hline & $68 F$ & 0 & 1 & 1 & 0 & 0 & 0 & 0 & 0 & 0 & 0 \\
\hline & $70 A$ & 2 & 1 & 0 & 0 & 0 & 0 & 0 & 0 & 0 & 0 \\
\hline & $70 F$ & 1 & 0 & 0 & 2 & 0 & 0 & 0 & 0 & 0 & 0 \\
\hline & $71 A$ & 1 & 0 & 1 & 0 & 0 & 1 & 0 & 0 & 0 & 0 \\
\hline & $71 F$ & 0 & 0 & 2 & 1 & 0 & 0 & 0 & 0 & 0 & 0 \\
\hline & $72 A$ & 0 & 3 & 0 & 6 & 0 & 0 & 0 & 0 & 0 & 0 \\
\hline & $74 A$ & 3 & 2 & 0 & 0 & 0 & 0 & 0 & 0 & 0 & 0 \\
\hline & $75 A$ & 1 & 0 & 4 & 0 & 0 & 0 & 0 & 0 & 0 & 0 \\
\hline & $75 C$ & 0 & 5 & 2 & 0 & 0 & 0 & 0 & 0 & 0 & 0 \\
\hline & $76 B$ & 1 & 0 & 2 & 1 & 0 & 0 & 0 & 0 & 0 & 0 \\
\hline & $78 A$ & 0 & 1 & 2 & 0 & 0 & 0 & 0 & 0 & 0 & 0 \\
\hline & $79 E$ & 1 & 2 & 0 & 1 & 0 & 0 & 0 & 0 & 0 & 0 \\
\hline \multirow[t]{41}{*}{$3 R$} & $79 F$ & 0 & 0 & 1 & 1 & 0 & 0 & 0 & 0 & 0 & 0 \\
\hline & $82 A$ & 2 & 0 & 0 & 1 & 0 & 0 & 0 & 0 & 0 & 0 \\
\hline & $82 F$ & 0 & 6 & 0 & 6 & 0 & 0 & 0 & 0 & 1 & 0 \\
\hline & $84 D$ & 0 & 0 & 7 & 1 & 0 & 0 & 0 & 0 & 0 & 0 \\
\hline & $84 E$ & 0 & 0 & 1 & 6 & 0 & 0 & 0 & 0 & 0 & 0 \\
\hline & $85 D$ & 0 & 2 & 3 & 2 & 0 & 0 & 0 & 1 & 0 & 0 \\
\hline & $85 E$ & 0 & 0 & 2 & 7 & 0 & 0 & 0 & 0 & 0 & 1 \\
\hline & $85 F$ & 0 & 0 & 1 & 1 & 0 & 0 & 0 & 0 & 0 & 0 \\
\hline & $86 B$ & 0 & 1 & 0 & 1 & 0 & 0 & 0 & 0 & 0 & 0 \\
\hline & $86 D$ & 0 & 0 & 2 & 1 & 0 & 0 & 0 & 0 & 0 & 0 \\
\hline & $86 F$ & 1 & 2 & 1 & 0 & 0 & 0 & 0 & 1 & 0 & 0 \\
\hline & $87 A$ & 4 & 0 & 3 & 0 & 0 & 1 & 0 & 0 & 0 & 0 \\
\hline & $87 B$ & 1 & 0 & 4 & 0 & 0 & 0 & 0 & 0 & 0 & 0 \\
\hline & $87 D$ & 1 & 0 & 2 & 2 & 0 & 0 & 0 & 0 & 0 & 0 \\
\hline & $87 E$ & 0 & 4 & 3 & 0 & 0 & 0 & 0 & 0 & 0 & 0 \\
\hline & $87 F$ & 3 & 0 & 1 & 1 & 0 & 1 & 0 & 0 & 0 & 0 \\
\hline & $88 B$ & 1 & 0 & 0 & 1 & 0 & 0 & 0 & 0 & 0 & 0 \\
\hline & $88 E$ & 0 & 1 & 0 & 2 & 0 & 0 & 0 & 0 & 0 & 0 \\
\hline & $89 A$ & 0 & 0 & 2 & 1 & 0 & 0 & 0 & 0 & 0 & 0 \\
\hline & $89 B$ & 0 & 0 & 1 & 3 & 0 & 0 & 0 & 0 & 0 & 0 \\
\hline & $90 A$ & 1 & 0 & 3 & 0 & 0 & 0 & 0 & 0 & 0 & 0 \\
\hline & $91 A$ & 0 & 0 & 1 & 3 & 0 & 0 & 0 & 0 & 0 & 0 \\
\hline & $91 B$ & 0 & 1 & 0 & 2 & 0 & 0 & 0 & 0 & 0 & 0 \\
\hline & $92 A$ & 3 & 2 & 1 & 1 & 0 & 0 & 0 & 1 & 0 & 0 \\
\hline & $93 E$ & 2 & 0 & 0 & 1 & 0 & 0 & 0 & 0 & 0 & 0 \\
\hline & $93 F$ & 0 & 0 & 1 & 9 & 0 & 0 & 0 & 0 & 0 & 0 \\
\hline & $94 A$ & 1 & 1 & 0 & 0 & 0 & 0 & 0 & 0 & 0 & 0 \\
\hline & $94 D$ & 0 & 8 & 1 & 0 & 0 & 0 & 0 & 0 & 0 & 0 \\
\hline & $95 F$ & 1 & 0 & 0 & 1 & 0 & 0 & 0 & 0 & 0 & 0 \\
\hline & $96 C$ & 1 & 0 & 0 & 1 & 0 & 0 & 0 & 0 & 0 & 0 \\
\hline & $96 \mathrm{~F}$ & 1 & 10 & 0 & 0 & 1 & 0 & 0 & 0 & 0 & 0 \\
\hline & $98 A$ & 2 & 2 & 0 & 0 & 0 & 0 & 0 & 0 & 0 & 0 \\
\hline & $98 B$ & 0 & 1 & 3 & 0 & 0 & 0 & 0 & 1 & 0 & 0 \\
\hline & $98 C$ & 1 & 1 & 2 & 0 & 0 & 0 & 0 & 0 & 0 & 0 \\
\hline & $98 D$ & 2 & 2 & 0 & 0 & 1 & 0 & 0 & 0 & 0 & 0 \\
\hline & $98 E$ & 4 & 1 & 0 & 0 & 1 & 0 & 0 & 0 & 0 & 0 \\
\hline & $98 F$ & 1 & 4 & 1 & 0 & 1 & 0 & 0 & 0 & 0 & 0 \\
\hline & $99 A$ & 1 & 0 & 2 & 0 & 0 & 0 & 0 & 0 & 0 & 0 \\
\hline & $99 B$ & 1 & 1 & 1 & 0 & 0 & 0 & 0 & 1 & 0 & 0 \\
\hline & $100 \mathrm{~A}$ & 8 & 0 & 1 & 0 & 0 & 1 & 0 & 0 & 0 & 0 \\
\hline & $100 B$ & 1 & 0 & 5 & 0 & 0 & 0 & 0 & 0 & 0 & 0 \\
\hline
\end{tabular}


Table 2 Probabilities of expected numbers of co-occurrences to be inferior and equal ( $\left.f_{\text {inf }}\right)$ or superior and equal $\left(f_{\text {sup }}\right)$, to observed values, for models 1,2 and 3 (see text). In models 1 and 2, since we used a two-tailed test, the probabilities are to be compared to 0.025 for a threshold value of 5 per cent. The statistic of the model 3 (the approximation of the Montgomery and Langley's statistics, see text) is to be compared to 2, the theoretical threshold of the normal law approximation. $N_{\mathrm{A}}, N_{\mathrm{B}}$ : number of sites where the element A (respectively B) is present in at least one line. $N_{A B}$ : observed number of sites where the $A$ element is present in at least one line and the $\mathrm{B}$ element is present on the same or another line. $M_{\mathrm{AB}}$ : observed number of hybridization sites with two $\mathrm{A}$ and $\mathrm{B}$ elements present simultaneously in a same line

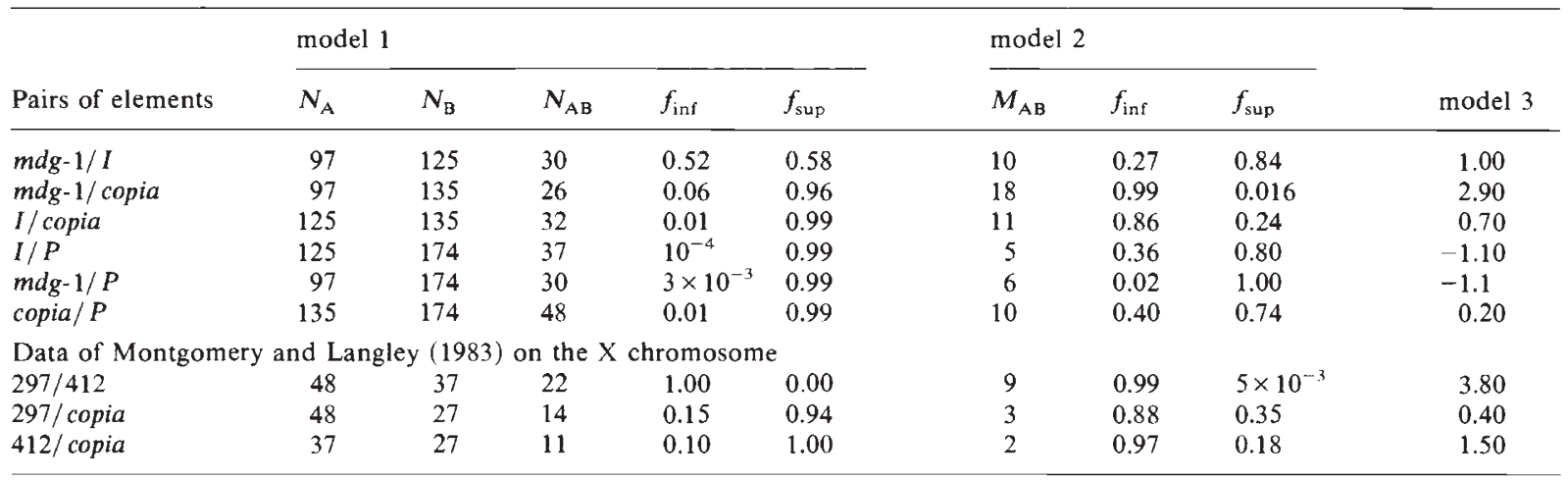

are randomly drawn from the 400 detectable ones; $N_{\mathrm{AB}}$ follows thus the hypergeometric law $\mathscr{H}(400 ;$ $\left.N_{\mathrm{A}} ; N_{\mathrm{B}}\right)$. We then calculated the probabilities of the expected number of common sites to be inferior or equal, and superior or equal, to $N_{\mathrm{AB}}$. Note that in this study we did not take into account the insertions in the centromeric regions. As seen table 2 all the associations between $P$ and any other element are highly significant, as is also the association between copia and $I$. The numbers of interline co-occurrences between these elements are less than expected, i.e., there is a low probability for a $P$ element to be found in sites where other elements can insert. The test is, however, not significant for the pair $m d g-1 / I$, suggesting that these elements inserted independently among the bulk of possible and detectable insertion sites, as already reported from the analysis of a mass-mated population (Biémont, 1986). Note, however, that the probability associated with the pair mdg-1/copia is low though not statistically significant; this means that the insertion pattern of copia is different enough to that of $m d g-1$, as already observed (Biémont and Gautier, 1988)

Co-occurrences may also correspond to insertions of two different elements in the same hybridization site in the same genome. For that to be tested statistical test must address specifically the similarities in insertion patterns occurring in the same genome or, as here, in the same inbred line. One problem with such data, however, is that the number of co-occurrences $\left(M_{\mathrm{AB}}\right)$ within a line is conditioned by the observed insertion patterns of the elements in the population (the ensemble of lines). The test must then take into account the variability of occupation of each site so as not to confuse true interactions between two elements with artificial co-occurrences due either to sites with a high frequency of insertions (as could result if shared positions were identical by descent because of inbreeding in the initial population; Biémont and Gautier, 1987; Leigh Brown and Moss, 1987) or to multiple occupations arising from the reduced number of sites which can be distinguished by the in situ hybridization method (Montgomery and Langley, 1983). We considered that when a facilitation (or exclusion) exists, then the associations of insertion sites of two elements within lines are not random but lead to more (or less) co-occurrences than expected when these associations are randomly drawn from the 17 ! possible ones. Hence, for every pair of elements we considered the true pattern of insertion sites for one element and we permutated the lines for the other element. From the 17 ! possible permutations, we randomly selected 1000 of them by a computer. From these 1000 runs we determined the total number of co-occurrences expected under the hypothesis of complete independency between the insertion sites. Note that the statistical analysis is free of any untestable biological assumption such as the independency between insertion sites in the population which is considered in other studies (Montgomery and Langley, 1983). This calculation was done for all the insertion sites. We then recorded the frequencies of the simulated mean numbers of co-occurrences per line inferior and equal, and superior and equal, to the observed 
value $\left(\Sigma M_{\mathrm{AB}} / 17\right)$. As seen in table 2 (model 2$)$, this analysis reveals that copia and $m d g-1$ have more sites in common than expected while $\boldsymbol{P}$ and $m d g-1$ tend to avoid each other. The analysis done on data from each chromosome arm, however, reveals the absence of interactions between $m d g-1$ and copia on the $\mathrm{X}$ chromosome: only the $2 \mathrm{~L}$ and the $3 \mathrm{R}$ chromosome arms had more co-occurrences than expected (table 3 ), while $m d g-1$ and $P$ interacted only on this X chromosome (table 4). No interaction is revealed for the other pairs $m d g-1 / I$, $I /$ copia, $I / P$ and copia / $P$.

Table 3 Probabilities of expected numbers of co-occurrences between $m d g-1$ and copia in each chromosome arm to be inferior and equal $\left(f_{\text {inf }}\right)$ or superior and equal $\left(f_{\text {sup }}\right)$, to observed values, for model 2 .

\begin{tabular}{lll}
\hline Chromosome arms & $f_{\text {inf }}$ & $f_{\text {sup }}$ \\
\hline $\mathrm{X}$ & 0.88 & 1.00 \\
2L & 1.00 & 0.00 \\
2R & 0.18 & 0.96 \\
3L & 0.29 & 1.00 \\
$3 \mathrm{R}$ & 0.98 & 0.08 \\
\hline
\end{tabular}

Table 4 Probabilities of expected numbers of co-occurrences between $m d g-1$ and $P$ in each chromsome arm to be inferior and equal $\left(f_{\text {inf }}\right)$ or superior and equal $\left(f_{\text {sup }}\right)$, to observed values, for model 2

\begin{tabular}{lll}
\hline Chromsome arms & $f_{\text {inf }}$ & $f_{\text {sup }}$ \\
\hline $\mathrm{X}$ & 0.05 & 0.99 \\
2L & 0.87 & 0.44 \\
2R & 0.83 & 0.46 \\
3L & 0.13 & 1.00 \\
3R & 0.14 & 0.99 \\
\hline
\end{tabular}

\section{DISCUSSION}

The preferential co-occurrences of insertions of copia and $m d g-1$ can be tested in one of our lines where a genome reshuffling for copia was recently reported (Biémont, Aouar and Arnault, 1987). At the 52nd brother-sister generation this line had 12 copia insertions, at the 69th generation it had 15 insertions but mostly in sites different from those in generation 52. At generation 52 there were no common insertion sites for $m d g-1$ and copia, but two sites were common at generation 69 after the reshuffling (Biémont, Aouar and Arnault, 1987). According to the respective numbers of $m d g-1$ and copia insertions in all the lines, the probability of having co-occurrences of $m d g-1$ and copia in two sites in this line was 0.06; this low value reinforces the idea that $m d g-1$ and copia had more insertion sites in common than expected. Moreover, the two common sites observed at generation 69 were new, i.e., they were not observed in the other lines. This strongly argues against the hypothesis that cooccurrences could express a linkage disequilibrium between very close sites.

We did not test for higher levels of co-occurrences, since the number of sites in which insertions were seen for three or four elements simultaneously was so low that statistical analysis was not possible. Note, however, that six sites $(3 \mathrm{~F}, 33 \mathrm{~A}$, $36 \mathrm{~B}, 42 \mathrm{~A}, 42 \mathrm{~B}, 92 \mathrm{~A})$ can be targets for the four elements $m d g-1$, copia, $I$ and $P$; of these the sites $42 \mathrm{~A}$ and 42B (see fig. 2 for examples of homologous insertions in the $42 \mathrm{~B}$ region) have already been reported as capable of bearing many different mobile elements (297, 412, copia, mdg-1, mdg-3, roo; see Potter et al., 1979; Strobel, Dunsmuir and Rubin, 1979; Pierce and Lucchesi, 1981; Young and Schwartz, 1981; Ananiev et al., 1984; Belyaeva, Ananiev and Gvozdev, 1984; Biémont, 1986; Biémont and Aouar, 1987; Leigh Brown and Moss, 1987; Montgomery, Charlesworth and Langley, 1987; Biémont and Gautier, 1988). Such sites may be nests of transposons as proposed in other studies (Gvozdev, 1981).

Montgomery and Langley (1983) have reported a higher than expected rate of co-occurrences of the copia-like elements 412 and 297 in the X chromosome while no interaction existed with the copia element. Since the model they used postulated the independency of the insertion sites, we have analysed their data with our models 1 and 2 and our data with a model 3 which used an approximation of the Montgomery and Langley's statistic. In the model 3 we calculated for every site, and we cumulated over all the sites, the values of the normalized hypergeometric law that the number of co-occurrences in each site follows. The statistic was then compared to 2 , the theoretical threshold of the normal law approximation. Notice, however, that this normal law approximation may not be good because of the very low values of the parameters of each of the hypergeometric law. As seen in table 2, the co-occurrences $m d g-1 /$ copia (on the whole genome) and $297 / 412$ (on the X chromosornes) are detected by all models (although with a probability of only 0.06 in model 1). The interactions between $m d g-1$ and $P$ on the whole genome of our lines are not detected, however, by the Montgomery and Langley's model, even when only the data on the $\mathrm{X}$ chromosomes were considered (the statistic is then equal to $\rightarrow 1.7$, data not shown). It is, therefore, of great importance in the analyses of insertion 
sites interactions to use reliable models, as model 2 , which imply neither strong biological untestable assumptions nor doubtful mathematical approximations.

It was concluded in other studies that transposable elements are autonomous with respect to one another (Ananiev et al., 1984). Here we propose that some genomes may have particular chromosomal environments (DNA sequence, local chromatin structure, etc.) suitable or unsuitable for insertion of different elements as could result if the elements themselves may interact in some way to attract, stabilize, or repulse each other. For example, the insertion of $m d g-1$ in a given site may favour insertion of a copia element and forbidden insertion of a $P$ element. This was not expected knowing the DNA sequences and structures of these elements. Indeed, it is generally accepted that $m d g-1$ and copia, which belong to the copialike elements bounded by $5^{\prime} \mathrm{TG} \cdots \mathrm{CA}^{\prime} 3$, and resemble vertebrate retrovirus proviruses, insert into the chromosome without obvious site specificity (Inouye, Yuki and Saigo, 1984). This is different to the behaviour of the $P$ element, which, like a prokaryote transposon, inserts with a high degree of location site specificity in the GC-rich consensus sequence GCCCAG (O'Hare and Rubin, 1983). Although this difference between the two kinds of elements may explain the specific pattern of localization of the $P$ element, as compared to the three other copia, $I$ and $m d g-1$ elements (Biemont and Gautier, 1988), this does not satisfactorily explain the avoidance of insertion sites between $m d g-1$ and $P$ in a same genome. These two elements appear thus to compete at least for some insertion sites. The absence of any kind of interference for insertion between $I$ and the other elements is compatible with the idea that insertions of the $I$ element seem to have some sequence specificity as a result of preferred target site sequences or of some feature of the adjacent DNA (Fawcett et al., 1986).

The existence of interactions between mobile elements is one of the numerous facts that any theory of mobile element dynamics should take into account to accurately explain the ways in which these elements invade and are maintained in natural populations (Brookfield, 1986). We can also envisage the existence in higher organisms of similar interactions for insertion between integrated forms of retroviruses which have been shown to integrate in a limited number of sites used as targets at very high frequency (Shih, Stoye and Coffin, 1988). Whether presence of specific elements may limit or favour insertions of pro- viruses should be of great importance to better understand and eventually control the behaviour of such undesirable elements in our own genome.

Acknowledgements We thank C. Arnault, D. Pontier and C. Terzian for comments on the manuscript. This work was supported by the Centre National de la Recherche Scientifique (URA 243) and the Association pour la Recherche sur le Cancer.

\section{REFERENCES}

ANANIEV, E. V., BARSKY, V. E., ILYIN, Y. V. AND RYZIC, M. V 1984. The arrangement of transposable elements in the polytene chromosomes of Drosophila melanogaster. Chromosoma, 90, 366-377

BELYAEVA, E. SP., ANANIEV, E. V. AND GVOZDEV, V. A. 1984 Distribution of mobile dispersed genes ( $m d g-1$ and $m d g-3$ ) in the chromosomes of Drosophila melanogaster. Chromosoma, 90, 16-19

BIÉMONT, C. 1986. Polymorphism of the $m d g-1$ and I mobile elements in Drosophila melanogaster. Chromosoma, 93, 393-397

BIÉMONT, ('. ANIS AOUAR, A. 1987. Copy-number dependent transpositions and excisions of the mdg-1 element in inbred lines of Drosophila melanogaster. Heredity, 58, 39-47

BIF́MONT, C., AOUAR, A. ANI) ARNAULT, C. 1987. Genome rcshuffling of the copia element in an inbred line of Drosophila melanogaster. Nature, 329, 742-744

BIÉMONT, C $\therefore$ AND GAUTIFR, C. 1987. Mdg-1 mobile element heterozygosity in Drosophila melanogaster. Heredity, 58, $167-172$.

BIÉMONT, C. AND GAUTIER, C. 1988. Localization polymorphism of $m d g-1$, copia, $I$ and $P$ mobile elements in the genomes of Drosophila melanogaster, from data of inbred lines. Heredity, 60, 335-346.

BIÉMONT, C., GAUTIER, C. AND HEIZMANN, A. 1988. Independent regulation of mobile element copy number in Drosophila melanogaster inbred lines. Chromosoma, 96 , $291-294$.

BIÉMONT, C. AND TERZIAN, C. 1986. Regulation in the number of mdg-1 mobile elements in inbred Drosophila melanogaster. Genetica, 71, 161-165.

BROOKFIELD, J. F. Y. 1986. The population biology of transposable elements. Phil. Trans. R. Soc. Lond., 312, 217 226.

1)I NOC:ERA, P. P. ANI) CASARI, G. 1987. Related polypeptides are encoded by Drosophila F elements, $I$ factors, and mammalian L1 sequences. Proc. Natl Acad. Sci. USA, 84, $5843-5847$.

EMORI, Y., SHIBA, T., KANAYA, S., INOUYE, S., YUKI, S. ANI) SAIC:O, K. 1985. The nucleotide sequences of Copia-related RNA in Drosophila virus-like particles. Nature, 315, 773 776.

FAWCETT, D. H., I.ISTER, C. K., KELLET, E. AND FINNEC;AN, D. I. 1986. Transposable elements controlling $I$-R hybrid dysgenesis in D. melanogaster are similar to mammalian LINEs. Cell, 47, 1007-1015.

GVOZDFV, V. A. 1981. The nature and functions of intercalary heterochromatin in Drosophila melanogaster. In Molecular Bases of Genetic Processes. Proc XIV Int Congr Genet., 3, $257-271$ 
ILYIN, Y. V., CHMELIAUSKAiTE, V. G., GEORGIEV, G. P. 1980. Double-stranded sequences in RNA of Drosophila melanogaster: relation to mobile dispersed genes. Nucleic Acid Res., 8, 3439-3457.

INOUYE, S., YUKI, S. AND SAIGO, K. 1984. Sequence-specific insertion of the Drosophila transposable genetic element 17.6. Nature, 310, 332-333.

LANGER-SAFER, P. R., LEVINE, M. AND WARD, D. C. 1982. Immunological method for mapping genes on Drosophila polytene chromosomes. Proc. Natl Acad. Sci. USA, 79, 4381-4385.

LEIGH BROWN, A. J. AND MOSS, J. E. 1987. Transposition of the $I$ element and Copia in a natural population of Drosophila melanogaster. Genet. Res., 49, 121-128.

MONTGOMERY, E. A. AND LANGLEY, C. H. 1983. Transposable elements in Mendelian populations. II. Distribution of copia-like elements in natural populations. Genetics, 104, 473-483.

MONTGOMERY, E. A., CHARLESWORTH, B. AND LANGI-EY, C. H. 1987. A test for the role of natural selection in the stabilization of transposable element copy number in a population of Drosophila melanogaster. Genet. Res, 49, 31-41.

OHARE, K. AND RUBIN, G. M. 1983. Structures of P transposable elements and their sites of insertion and excision in the Drosophila melanogaster genome. Cell, 34, 25-35.

PIERCE, D. A. AND LUCCHESI, J. C. 1981. Analysis of a dispersed repetitive DNA sequence in isogenic lines of Drosophila melanogaster. Chromosoma, 82, 471-492.
POTTER, S. S., BROREIN, W. J., DUNSMUIR, P. AND RUBIN, G. M. 1979. Transposition of elements of the 412 , copia, and 297 dispersed repeated gene families in Drosophila. Cell, 17, 415-427.

RIGBY, P. W., DIECKMANN, M., RHOIDES, C. ANI) BERG, P. 1977. Labeling deoxyribonucleic acid to high specific activity in vitro by nick translation with DNA polymerase I. J. Mol. Biol. 113, 237-251.

SHIH, C-C., STOYE, I. P. AND COFFIN, I. M. 1988. Highly preferred targets for retrovirus integrations. Cell, 53, 531-537.

STROBEL, F., DUNSMUIR, P. AND RUBIN, G. M. 1979. Polymorphisms in the chromosomal locations of elements of the 412, Copia and 297 dispersed repeated gene families in Drosophila. Cell, 17, 429-439.

TCHURIKOV, N. A., ILYIN, Y. V., SKRYABIN, K. G., ANANIEV, E. V., BAYEV, A. A., KRAYEV, A. S., ZELENTSOVA, E. S., KULGUSKIN, V. V., LYUBOMIRSKAYA, N. V. AND GEORGIEV, G. P. 1981. General properties of mobile dispersed genetic elements in Drosophila. Cold Spring Harbor Symp. quant. Biol. 45, 655-665.

YOLNG, M. V. AND SCHWARTZ, H. E. 1981. Nomadic gene families in Drosophila. Cold Spring Harbor Symp. quant. Biol., 45, 629-640. 